\title{
EDITORIAL
}

\section{El Profesor Claudio Donoso Zegers, una huella de bosque en los jóvenes}

\author{
Víctor Gerding
}

Editor

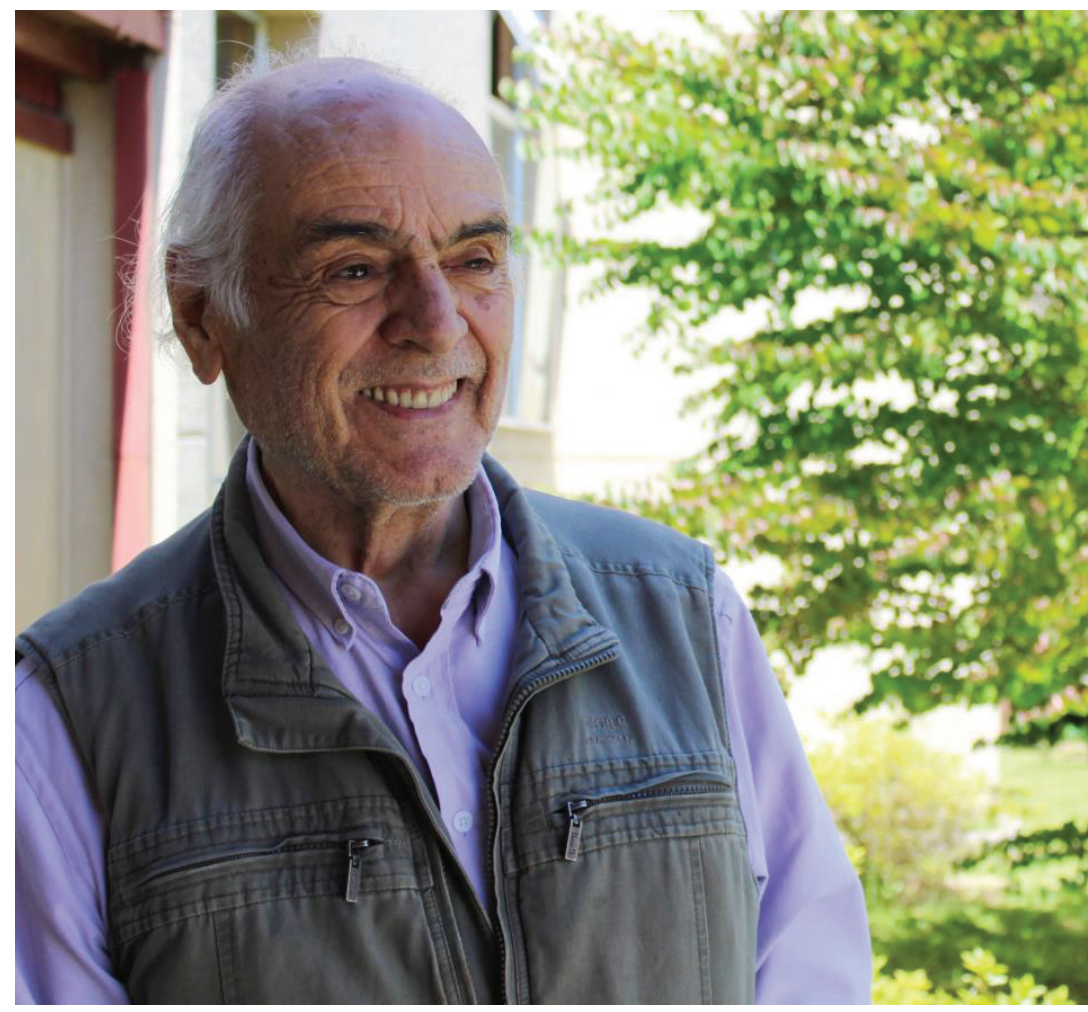

Claudio Donoso Zegers, ingeniero forestal de la Universidad de Chile y Master of Science de la Universidad de California (EE.UU.), desarrolló su amplia y productiva vida universitaria en la Facultad de Ciencias Forestales y Recursos Naturales de la Universidad Austral de Chile, en Valdivia, donde encontró suelo fértil y bosque frondoso para crear y crecer. Desde allí desplegó su pasión por los bosques nativos y la naturaleza en general, desarrollando una exuberante producción académica para los estudiantes, profesionales, académicos, científicos y -con especial esmero- para comunicarle a toda la gente los valores y secretos de árboles y bosques. Su voluminosa obra escrita se ha expresado en muchos artículos científicos, libros, informes técnicos y otros textos que cuentan varios miles de páginas. Aunque, como él mismo se define, es esencialmente un hombre de libros, de los cuales ha escrito los más importantes sobre ecología forestal, dinámica de bosques, silvicultura $\mathrm{y}$, en general, sobre bosques nativos de Chile.

En su currículo se encuentran varios premios de gran importancia, como, por ejemplo, Reconocimiento de CONAF y Ministerio de Agricultura por labor desarrollada por el bosque nativo (1994). Premio Luis Oyarzún, de la Universidad Austral de Chile (1999), cuyo propósito es entregar un merecido reconocimiento a personalidades que hayan contribuido en forma destacada, a través de la ciencia o el arte, al logro de relaciones armónicas entre seres humanos y la naturaleza. En este caso, fueron destacadas su contribución científica para el conocimiento profundo de los bosques nativos de Chile y su personal compromiso en la protección de los mismos. En el año 2000, la Uni- 
versidad Austral de Chile lo nombró Profesor Emérito. El Colegio de Ingenieros Forestales de la Región de Los Lagos (2002) lo premió por su excelencia y aporte al conocimiento de los bosques nativos. Luego, en 2007, recibió el Reconocimiento a la Trayectoria por parte del Colegio de Ingenieros Forestales de Chile. El 2009 nuevamente fue premiado, esta vez por la Universidad Católica de Temuco, por su destacada trayectoria académica y como experto en el desarrollo sostenible del bosque nativo.

Durante su vida académica activa en la Facultad de Ciencias Forestales y Recursos Naturales se desempeñó en los cargos de Director de Instituto y Prodecano, y también en proyectos de interés institucional para favorecer la divulgación de la ciencia, siendo coeditor de la revista Bosque en la década de 1980. Sin embargo, esta revista fue fortalecida, principalmente, mediante los numerosos artículos científicos que en ella publicó Claudio Donoso Zegers, como autor o coautor, dándole a Bosque un sello y reconocimiento internacional en torno a los bosques nativos del Cono Sur de Sudamérica. Muchos de sus trabajos están entre los artículos “clásicos” que siempre se citan hasta hoy.

Entre sus aportes más destacados en las ciencias de los bosques nativos están los estudios precursores de genecología del género Nothofagus en Chile, donde una contribución relevante fue demostrar que $N$. leonii es un híbrido entre $N$. glauca y $N$. obliqua. También fue pionero en mostrar la importancia científica y valor de conservación de los bosques del género Nothofagus de la zona mediterránea de Chile, hoy reconocida como una de las de mayor biodiversidad biológica, con especies restringidas solo a ese territorio del planeta. Una parte importante de su desarrollo científico lo dedicó al estudio de la estructura y dinámica de bosques de los tipos forestales siempreverde y alerce, incluyendo ciclos de semillación en los bosques. Para ello, instaló los ensayos más extensos en superficie y de más larga duración que se han desarrollado en los bosques de Chile. Otro de sus aportes muy significativos fueron sus investigaciones sobre semillas, técnicas de vivero, ciclos de producción y plantaciones de varias de las especies forestales nativas. En esto, fue impulsor y gestor del Vivero Experimental de Especies Nativas y del Laboratorio de Semillas de Especies Nativas que han sido elementos relevantes para la investigación científica y docencia de pre y posgrado de la Universidad Austral de Chile. Todo su trabajo científico fue desarrollado a través de cuantiosos proyectos de investigación que dirigió, en los cuales hubo participación para el financiamiento y cooperación técnica de parte del Estado y de empresas privadas interesadas en explorar opciones de manejo de bosques nativos. Así, Claudio Donoso Zegers buscó siempre aportar al conocimiento y generar las bases -sistemas silviculturales- para un manejo sostenible de los bosque nativos, mediante una relación directa de la ciencia con los ambientes forestales y de gestión empresarial que la aplica. En todo esto, el trabajo acucioso en el bosque, por largas e innumerables jornadas, lo caracterizó y fortaleció.

Otra área donde Claudio Donoso Zegers es un referente nacional indiscutido corresponde a la política nacional con su aporte para valorar los bosques y beneficiar a la sociedad. En este contexto, participó activamente en el diseño de políticas, leyes y reglamentos para los bosques nativos de Chile. Un importante hito fue la creación de la tipología forestal para Chile (1981), en la cual él condujo al equipo técnico que desarrolló dicha clasificación y que está consagrada en la legislación forestal del país. De especial significancia fue su perseverante trabajo de apoyo técnico y promoción de la aprobación de la Ley № 20283 sobre Recuperación del Bosque Nativo y Fomento Forestal. Para fortalecer la opinión con base técnica en el ámbito de la política sectorial y comunicar esto a la sociedad, contribuyó a la creación y desarrollo de la Agrupación de Ingenieros Forestales por el Bosque Nativo (AIFBN), en la cual demostró su liderazgo, convicción y solidez de sus fundamentos, por lo que fue elegido como miembro del Directorio en varias oportunidades y fue reconocido como su Presidente Emérito, porque su opinión es escuchada como la del más conocedor del bosque nativo.

No obstante la profusa obra que Claudio Donoso Zegers ha materializado en los temas antes mencionados, sin duda, lo más importante de su quehacer profesional ha sido su rol de Profesor universitario en la ingeniería forestal. Él ha llevado a la docencia a su sublime esencia: observó y aprendió a observar más profundo, para luego guiar activamente a los estudiantes hacia una observación interesada, admirada, atenta y expectante de la realidad, tanto del bosque como del ser humano; escuchó y aprendió a escuchar más intensamente para dialogar en una comunicación creativa con sus interlocutores, ya sean campesinos, estudiantes o científicos; otorgó a las ideas su valor y sentido significativo, distinguiendo y transmitiendo nítidamente los conceptos esenciales; y posibilitó, apoyando y creando, instancias de transformación imprescindibles para que tenga 
sentido el aprendizaje, incluyendo materias nuevas que no se enseñaban hasta entonces en la ingeniería forestal. Actualmente, continúan aplicándose las innovaciones que impulsó en técnicas de enseñanza-aprendizaje, integrando la teoría con la práctica y fundiendo el aula con el bosque. Su labor docente se caracterizó por disfrutar enseñando y por el respeto hacia los estudiantes, encontrando alguna forma especial para que cada uno de ellos demostrara y fortaleciera su conocimiento y aprendizaje, mediante su trato directo como a sus iguales, compartiendo los sueños y problemas de ellos, incluso apoyando materialmente a estudiantes de escasos recursos. Así, con muchos de sus exalumnos conserva una genuina amistad nacida en esos tiempos de las aulas y trabajo en terreno. No dejó oportunidad de responder cada carta que recibió, de escolares a ministros, y siempre estaba disponible para atender las consultas de los numerosos estudiantes que llegaban a su oficina, permanentemente con la puerta abierta. Como parte de su enseñanza, se preocupó por el bienestar de toda la gente que trabajaba con él en cualquier rol de su participación dentro del equipo de trabajo.

Claudio Donoso Zegers siempre ha trabajado en equipo, con gran cantidad de personas e instituciones, lo que demuestra en el fondo su carácter afable. En ese conjunto humano hay destacadísimos profesores universitarios de muchas latitudes del mundo y, por supuesto, también de Chile; científicos, profesionales, técnicos, obreros, campesinos forestales, estudiantes de diversos niveles, personal de labores administrativas, etc.

Otro de sus rasgos característicos es su actuar con determinación, basado en principios de justicia y equidad. Así, y con valentía, le tocó desenvolverse en medio de una dictadura que aquejaba a nuestra sociedad, apoyando a los desvalidos y víctimas. También, ha sido probo y austero en su vida, la que ha conducido consecuentemente con sus principios. De esta manera, comprendiendo la dinámica humana e institucional, Claudio Donoso Zegers ha sabido retirarse a tiempo (a las 65 años, en el 2000) de su cargo de Profesor Titular de la Facultad de Ciencias Forestales y Recursos Naturales de la Universidad Austral de Chile, dejando aquel espacio para otros académicos jóvenes, y así comenzar una nueva etapa de su vida, en la cual continúa observando, reflexionando, creando, escribiendo y enseñando.

Como corolario, Claudio Donoso Zegers ha tenido un éxito único en motivar a generaciones de silvicultores y ecologistas chilenos, principalmente entre los ingenieros forestales. Durante décadas ha sido la "conciencia” vigilante de los bosques nativos chilenos, estableciendo un estándar para todos los que valoran estos bosques, para respetar y emular. Ha dejado una profunda huella como persona, profesor universitario, investigador científico y profesional íntegro que es visto como un modelo a seguir por muchísimos estudiantes de varias generaciones.

\section{AGRADECIMIENTOS}

Por su valioso y gentil aporte en información e ideas para esta editorial, agradezco especialmente a:

- Marcos Cortés Bianchi, ingeniero forestal, magíster en ciencias mención silvicultura.

- Magdalena Donoso Hiriart, periodista.

- Bernardo Escobar Rodríguez, técnico forestal, téctico académico y encargado del Vivero Experimental de Especies Nativas y del Laboratorio de Semillas de Especies Nativas, de la Universidad Austral de Chile.

- Mauro González Cangas, ingeniero forestal, PhD, profesor titular de la Universidad Austral de Chile.

- Antonio Lara Aguilar, ingeniero forestal, PhD, profesor titular de la Universidad Austral de Chile.

- René Reyes Gallardo, ingeniero forestal, PhD, investigador del Instituto Forestal, Valdivia.

- Loreto Rojas Tello, periodista de la Facultad de Ciencias Forestales y Recursos Naturales; también se le agradece por la fotografía.

- Tom Veblen, bachiller en geografía, PhD, Professor of Distinction de la Universidad de Colorado, Estados Unidos. 
